\title{
МЕТОДИЧЕСКИЙ ПОДХОД К ОЦЕНКЕ ЭФФЕКТИВНОСТИ ДЕЯТЕЛЬНОСТИ УЧАСТНИКОВ ПРОСТРАНСТВЕННОГО КЛАСТЕРА
}

\author{
(C) 2019 Морозова Екатерина Владимировна \\ директор по развитию \\ ООО «Производственная компания «Корстэл» \\ 398007, г. Липецк, пл. Заводская, 1 \\ E-mail: evmorozova26@mail.ru
}

\begin{abstract}
Проблема выбора наиболее эффективного состава региональных кластеров для формирования недостающих звеньев становится все более актуальной. Применение подходов к пространственной кластеризации экономики, позволяющих усилить взаимосвязи хозяйствующих субъектов в регионе, позволяет выявить критерии эффективности деятельности участников подобных кластеров. В статье рассматривается комплексная методика оценки внешних и внутренних факторов, влияющих на успешное функционирование и развитие участников кластерных объединений, предложена система индикаторов, применяемая для измерения эффективности пространственных кластеров.
\end{abstract}

Ключевые слова: региональный кластер, пространственная кластеризация, критерии эффективности кластера, оценка эффективности.

Широкое распространение пространственной кластеризации промышленности по всему миру в большинстве своем, объясняется экономическими перспективами и положительным синергетическим эффектом, который дает всем участникам кластера кооперационное взаимодействие.

Конкурентоспособность компаний складывается из многих факторов как на национальном, так и на региональном рынке. Поставщики, заказчики продукции, инновационная и технологическая инфраструктура, научные и исследовательские организации составляют непосредственное окружение, а макроэкономические факторы и ресурсы для промышленных кластеров относятся к национальному уровню [1].

Непосредственное окружение характеризует среду для развития пространственных кластеров. Термин «пространственный кластер» подразумевает под собой определенный вид кооперационного взаимодействия всех его участников, расположенных на относительно компактной территории и ориентированных совей деятельностью на выпуск конкурентоспособного вида продукции. Пространственный кластер отличается от других форм территориальной концентрации производства тем, что он в существенной мере «встроен» в пространство своей дислокации, черпая из нее новые возможности, предоставляемые территориальной инфраструктурой, особенностями пространственной конфигурации производств, возможностями экономико-географического положения. Поэтому пространственные кластеры в силу их многоуровневости связывают с развертыванием макротехнологической революции [2].

При применении методологии кластерного анализа к типовой модели пространственного кластера стоит обратить внимание на внешние и внутренние факторы, влияющие на успешное функционирование и развитие кластерных объединений, и выявить критерии эффективности подобных кластеров.

Международная практика показывает, что кластеры, представляющие собой группу взаимосвязанных компаний, функционирующих на одной территории и работающие в смежных областях, формируют основу конкурентоспособности региона.

Планомерная и обоснованная кластерная политика является залогом повышения конкурентоспособности региона по нескольким факторам. Во-первых, кластерная политика вписывается в политику развития региона и повышения его конкурентоспособности. Во-вторых, способствует активному диалогу между главными участниками (администрация, бизнес, высшие учебные заведения, региональная элита и т.д.), достижению общих целей и разработке плана для всех заинтересованных сторон. В-третьих, позволяет сгладить противоречия между производительностью и занятостью, благодаря 
специализации и аутсорсингу непрофильных видов деятельности, а также благодаря интеграции новых экономических игроков, работающих в смежных и взаимодополняющих областях. Что не маловажно, политика пространственной кластеризации способствует международной коммуникации и позволяет привлечь инвесторов путем продвижения территориальных компетенций.

Принимая во внимание вышеперечисленные факторы, влияющие на конкурентоспособность региона, для дальнейшего определения критериев эффективности региональных кластеров обозначим существенный принцип стратегии пространственной кластеризации, который гласит так: возможно успешное инициирование и управление кластером там, где имеется критическая масса, необходимая для возникновения кластера [3]. Именно «критическая масса» дает понимание о стратегической направленности менеджмента на месте локализации кластера, который и обеспечит его эффективное функционирование.

Согласно теории «критической массы» для формирования полноценного кластера необходимо достижение определенной концентрации его участников (количество фирм, количество занятых), обусловливающей переход от количества к качеству (достижение синергетического эффекта). Накопленный в европейских странах опыт показывает, что для достижения критической массы, необходимой для создания кластера, требуется, чтобы в его состав вошло не менее 30-50 организаций [4].

Взяв за основу данный принцип, схематически представим различие между кластерным потенциалом и эффективными кластерными структурами (рисунок 1).
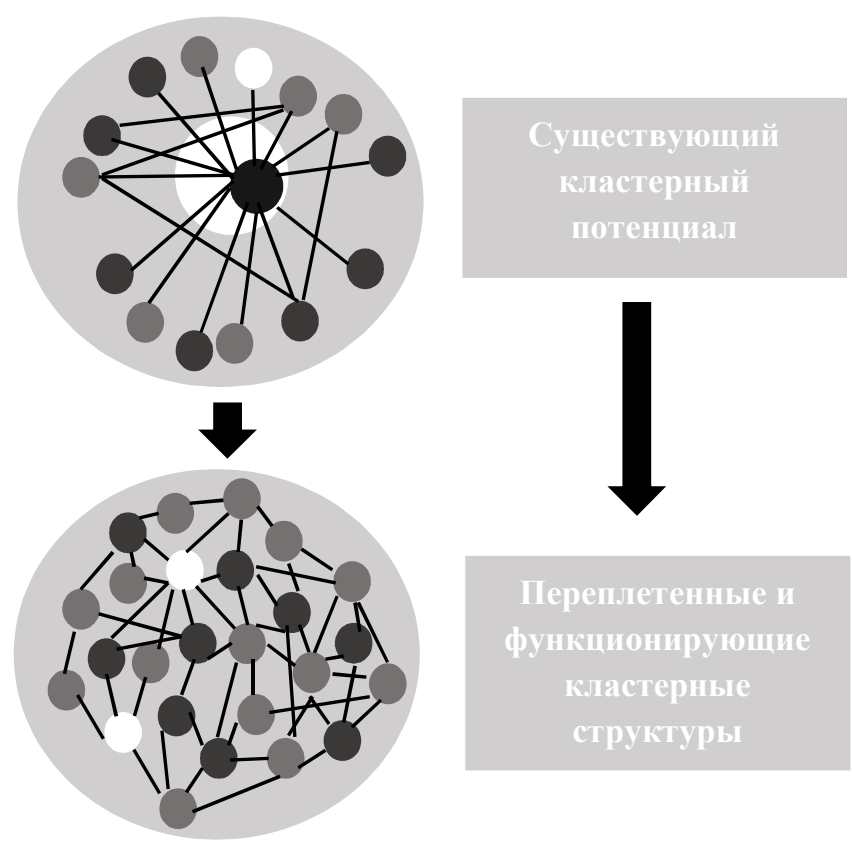

Управляющая компания

НИИ, ВУЗы

Крупные, малые и

средние компании

Прочие участники: финансовые

структуры, тренинги, содействие экономическому развитию

Рис.1. Различие между кластерным потенциалом и кластером 
Из рисунка 1 видно, что становление пространственного кластера во многом определяется не только его структурными элементами, но и их комбинаторным сочетанием. Хотя набор предприятий кластера известен, но выбрать из их производственных программ нужный для обеспечения синергетического эффекта объем производства без экономико-статистического инструментария сложно. Но перед этим надо определиться и с критическими показателями-индикаторами, должным образом наполняющими предпосылки формирования пространственного кластера. Предпосылками состоявшегося кластера можно считать:

- Структурные предпосылки (критическая масса участников, специализированные потребители, поставщики сырья и комплектующих, наличие связей с ВУЗами и НИИ, возможности для прямых неформальных контактов, инновационные процессы внутри кластера (конкуренция и кооперация).

- Институциональные предпосылки (политический курс региональной власти, знание механизмов кластера).

- Готовность и способность якорных участ- ников кластера к сотрудничеству.

При анализе научных работ по вопросам оценки эффективности кластеров необходимо отметить многообразие существующих подходов. В качестве критериев эффективности рассматривается оценка по совокупному объему производства, по экономии на издержках, по степени инновационности, по эффективности якорных предприятий и т.д.

Проанализировав подходы к определению многочисленных критериев эффективности, следует систематизировать индикаторы, применяемые для оценки эффективности кластеров (рисунок 2).

Три основных блока критериев: «Связи и партнерства», «Инновации и НИОКР», «Человеческие ресурсы» всесторонне характеризуют деятельность участников кластера и формируют наборы индикаторов, которые в последующем ложатся в основу экономической политики как якорных участников кластера, так и региональной политики в целом.

Оценивая на предварительном этапе синергетический эффект кластера, стоит обратить внимание на вклад каждого участника в общую

\begin{tabular}{|c|c|c|c|}
\hline \multicolumn{4}{|c|}{ Региональная экономика и экономика предприятий } \\
\hline \multirow{6}{*}{\multicolumn{2}{|c|}{$\begin{array}{l}\text { * кол-во созданных рабочих мест } \\
\text { * рост существующего бизнеса } \\
\text { * оборот предприятий } \\
\text { * уровень инвестиций } \\
\text { * объем продаж на экспорт } \\
\text { * привлечение новых иностранных } \\
\text { предприятий }\end{array}$}} & \multicolumn{2}{|c|}{ * иностранные инвестиции } \\
\hline & & \multirow{2}{*}{\multicolumn{2}{|c|}{ * кол-во портнерских программ и }} \\
\hline & & & \\
\hline & & \multicolumn{2}{|c|}{ * создание новых обучающих } \\
\hline & & \multicolumn{2}{|c|}{ программ } \\
\hline & & \multicolumn{2}{|c|}{ * кол-во предприятий } \\
\hline \multirow{4}{*}{$\begin{aligned} & \text { Связи и партнерства } \\
\text { * } & \text { кол-во партнеров } \\
\text { * } & \text { кол-во соглашений о } \\
\text { сотрудничестве } & \text { * }\end{aligned}$} & \multirow{5}{*}{\multicolumn{2}{|c|}{\begin{tabular}{|l}
\multicolumn{1}{|l}{ Инновации и НИОКР } \\
* кол-во персонала, \\
работающего в НИОКР, \\
затраты на НИОКР \\
* кол-во созданных новых \\
предприятий, основанных \\
на результатах \\
исследований
\end{tabular}}} & भеловече \\
\hline & & & * кол-во рабоч \\
\hline & & & * poc \\
\hline & & & * кој ц ц \\
\hline $\begin{array}{l}\text { * кол-во организованных } \\
\text { мероприятий для }\end{array}$ & & & \\
\hline укрепления связей & \multirow{2}{*}{\multicolumn{2}{|c|}{ * кол-во патентов }} & \\
\hline $\begin{array}{l}\text { * кол-во совместных } \\
\text { исследований }\end{array}$ & & & \\
\hline $\begin{array}{l}\text { * кол-во } \\
\text { вопросов/проблем, }\end{array}$ & \multicolumn{3}{|c|}{$\begin{array}{l}\text { достижений (премий, } \\
\text { наград) }\end{array}$} \\
\hline $\begin{array}{l}\text { разрешенных совместн } \\
\text { кластере }\end{array}$ & \multicolumn{3}{|c|}{$\begin{array}{l}\text { * кол-во созданных новых } \\
\text { продуктов или процессов }\end{array}$} \\
\hline
\end{tabular}

Puc. 2. Система индикаторов, применяемых для измерения эффективности кластеров 
эффективность объединения согласно выявленным индикаторам.

Эффективность компаний кластера - это подход к определению общей эффективности, характеризующийся переходом от принципа экономии, достигаемой за счет масштабов производства, к более широкому принципу стратегической экономии, основой которой является взаимная поддержка различных участников кластерных формирований [5].

Поскольку эффективность деятельности промышленных предприятий регионального кластера зависит от многих факторов, целесообразно в этой связи разработать методический подход для наиболее эффективной оценки влияния внешних и внутренних факторов на функционирование и развитие предприятий-участников кластера. Кроме того, с применением инструментария такого методического подхода появляется возможность:

1) устанавливать оптимальное соотношение между объемом производства, затратами и прибылью;

2) определять вклад, который вносит в покрытие затрат и формирование финансовых результатов каждая производственная единица кластера;

3) выявлять границы финансовой устойчивости и запаса финансовой прочности промышленного предприятия, входящего в территориальный кластер.

Применение математического аппарата для оценки влияния различных факторов на эффективность функционирования всего кластерного объединения с учетом значений ярко выраженных индикаторов, описанных выше, станет основой для принятия оперативных управленческих решений и выполнения стратегических задач, направленных на усиление инновационной составляющей и повышение конкурентоспособности пространственного кластера в целом [6]. Такой подход дает возможность составить экономико-математическую модель, в которой изменяя параметры, можно отслеживать изменение показателей эффективности при различных комбинациях исследуемых факторов. Это имеет важнейшее значение с точки зрения формирования стратегии развития предприятий пространственного кластера, планирования его текущей и перспективной деятельности, оценки возможных последствий принятия управленческих решений и т.д.
В качестве главного показателя эффективности при данном подходе будем использовать величину общей прибыли, формируемую всеми участниками пространственного кластера.

Взаимосвязь основных факторов, оказывающих наибольшее влияние на формирование прибыли Р участника пространственного кластера, представим следующим образом:

$$
P=\sum i j[V i j \times(P P i j-P C i j-E C i j)]
$$

где $\mathrm{V}$ - объем реализованной продукции в натуральном выражении, т;

PР - средняя цена единицы продукции, руб.;

PC - себестоимость (без учета энергетических затрат) единицы продукции, руб.;

EC - энергетические затраты на единицу продукции, руб.;

i - номер предприятия в кластере;

j - номер вида продукции.

Необходимо отметить, что выделение энергетических затрат в качестве одного из самостоятельно анализируемых факторов объясняется тем, что высокий уровень энергоемкости производства российских предприятий пространственных кластеров, производящих инновационную продукцию, является одной из причин, сдерживающих повышение их конкурентоспособности на мировом рынке.

В соответствии с предложенным методическим подходом анализ прибыли каждого участника пространственного кластера предлагается проводить в несколько этапов. В первую очередь определим силу операционного рычага по каждому фактору.

Для каждого сочетания і и j действие операционного рычага проявляется в том, что любое изменение анализируемого фактора всегда порождает более сильное изменение прибыли.

Для определения силы операционного рычага будем использовать следующие модели:

$$
\begin{aligned}
& D O L v=\frac{\mathrm{P}}{M R} \\
& D O L p p=\frac{\mathrm{P}}{S P} \\
& D O L p c=\frac{\mathrm{P}}{P S} \\
& D O L \text { ec }=\frac{\mathrm{P}}{E C}
\end{aligned}
$$


где DOL - сила операционного рычага по анализируемому фактору:

DOL v - сила операционного рычага по объему реализации;

DOL pp - сила операционного рычага по цене;

DOL pc - сила операционного рычага по себестоимости без учета энергетических затрат;

DOL ec - сила операционного рычага по энергетическим затратам;

MR - маржинальный доход, руб.;

P - прибыль, руб.;

SP - выручка от реализации продукции, руб.;

PC - себестоимость без учета энергетических затрат, руб.;

EC - энергетические затраты, руб.

На втором этапе проводится анализ чувствительности валовой прибыли предприятия участника кластера к изменению одного из факторов. Для этого будем использовать следующую модель:

$$
P \%=D O L \times F \%
$$

где Р\% - процентное изменение прибыли,\%;

F\% - процентное изменение анализируемого фактора,\%.

На третьем этапе проводится анализ безубыточности, который отличается от традиционного тем, что его целью является нахождение точки безубыточности и запаса финансовой прочности, имеющих отношение только к объему реализации производимой продукции. Запасом финансовой прочности будем считать тот объем выручки, на который в настоящий момент времени предприятие превышает ее критическое значение.

Технология проведения операционного анализа, в основе которой лежит классический анализ безубыточности производства, позволяет адаптировать его не только к объему реализации, но и к исследованию влияния других факторов, таких как: затраты и цена. Для этого определим точку безубыточности и запас финансовой прочности для каждого элемента операционного рычага по следующим моделям:

$$
\begin{aligned}
& F S M \%=\frac{1}{\mathrm{DOLF} \times 100} \\
& F S M=F \times F S M \% \\
& B E P \%=F \times \frac{(1-1)}{D O L F}
\end{aligned}
$$

где ВЕР - точка безубыточности, \%;

FSM\% - запас финансовой прочности, \%;

FSM - запас финансовой прочности, руб.

Таким образом, операционный анализ якорных участников пространственного кластера - это анализ результатов деятельности предприятий на основе исследования соотношения прибыли и затрат, позволяющий определить взаимосвязи между ними при разных объемах производства.

Подводя итог можно сделать вывод, что предложенный методический подход с использованием методов операционного анализа, дает возможность оценить влияние различных факторов на эффективность участников пространственного кластера, выбирая при этом наиболее предпочтительный вариант сочетания основных критериев эффективности с точки зрения достижения конечных результатов якорных предприятий. Для получения взвешенной оценки эффективности функционирования всего регионального кластера, в дальнейших исследованиях необходимо ставить вопрос о математической модели общих кластерных эффектов, оказывающих влияние как на каждое отдельное предприятие, так и на экономику региона в целом.

\section{Библиографический список}

1. Морозова E.В. Анализ влияния региональных и федеральных структур на развитие кластерных объединений // Экономика и предпринимательство. 2017. № 9 (ч.2). С. 233-237.

2. Попадюк Н.К. Города и пространственные кластеры в развертывании макротехнологической революции // Актуальные проблемы и перспективы развития государственного управления и права: Сборник научных статей V международной научно-практической конференции «Управленческие науки в современном мире». Под ред. С.Е. Прокофьева [и др.]. 2018. С. 146-153.

3. Розанова Н.М., Костенко Е.Д. Инновационные кластеры и кластерная политика государства: провалы рынка vs провалы государства // Terra Economicus. 2014. T. 12. № 1. С. 41-52. 
4. Руководство по формированию кластеров - основные направления формирования и управления кластерными инициативами (2009). Внутриевропейская Связь Кластеров. Перевод МИГСУ РАНХиГС при Президенте РФ. С.11.

5. Буянова М.Э., Дмитриева Л.В. Оценка эффективности создания региональных инновационных кластеров // Вестник Волгоградского государственного университета. Серия 3: Экономика. Экология. 2012. № 2 (21). С. 54-62.

6. Дырдонова А.Н., Андреева Е.С., Фомин Н.Ю. Оценка влияния различных факторов на эффективность деятельности предприятий регионального кластера // Научное обозрение. 2015. № 18. С. 247-249.

Поступила в редакцию 15.01.2019 